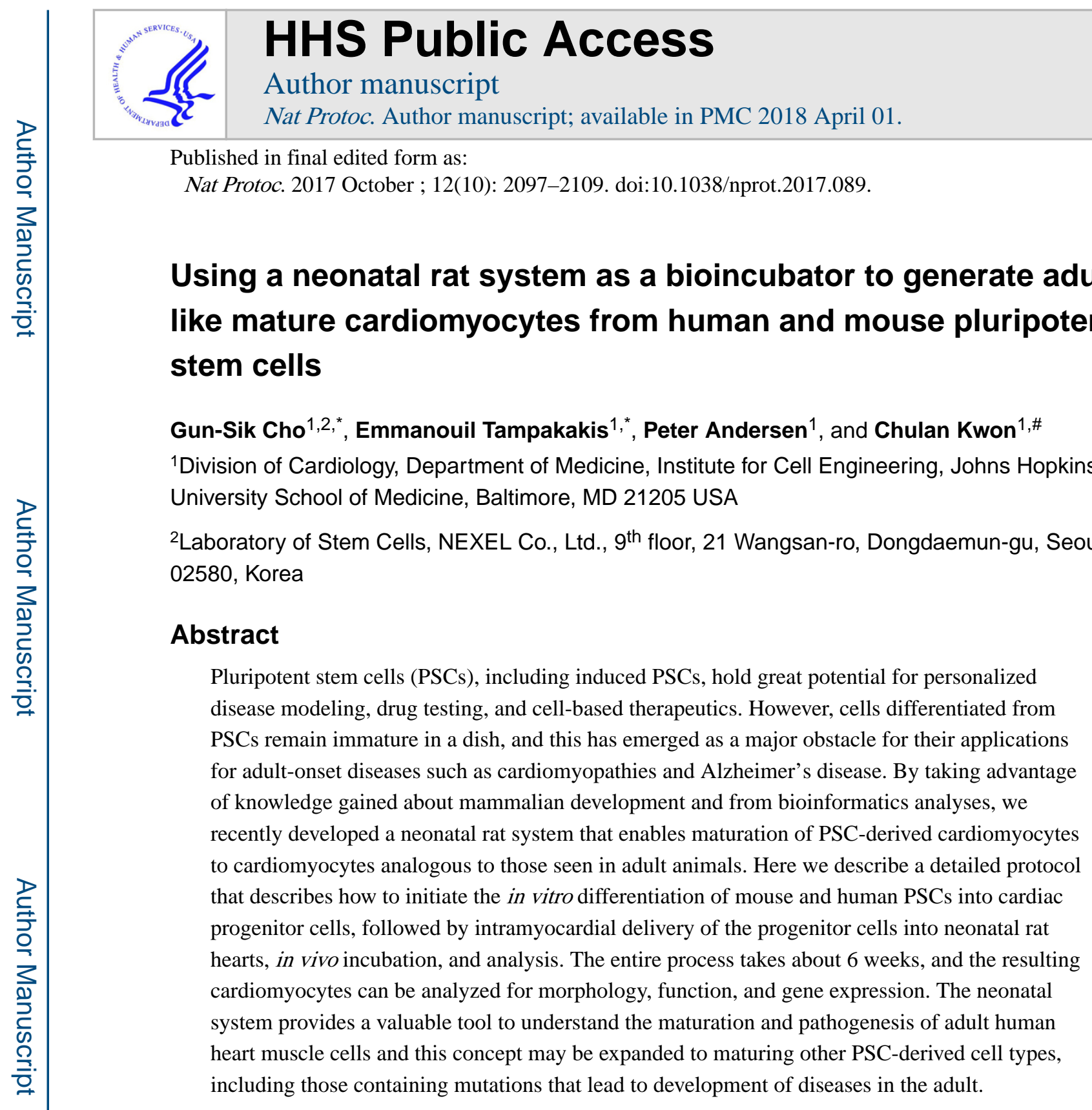

\title{
INTRODUCTION
}

Human induced pluripotent stem cells (hiPSCs) were first described in 2007 after Takahashi and colleagues reprogrammed somatic cells with certain transcription factors ${ }^{1}$. hiPSC can differentiate into any cell type of the body and thus hold great promise for disease modeling, drug discovery, repairing non-regenerative organs and studying human development ${ }^{2,3}$.

\footnotetext{
${ }^{\#}$ To whom correspondence should be addressed: Chulan Kwon, Ph.D., Division of Cardiology, Department of Medicine, Institute for Cell Engineering, Johns Hopkins University, Baltimore MD 21205, Phone: 410-502-2154, Fax: 443-287-6638, ckwon13@jhmi.edu. Co-first author

AUTHOR CONTRIBUTIONS

G.C. and C.K. designed the experiments. G.C., E.T., and P.A. performed the experiments. G.C., E.T., and P.A. analyzed the data. E.T. and P.A. made the figures. E.T., G.C., P.A., and C.K wrote the manuscript. All authors approved the manuscript.

COMPETING FINANCIAL INTERESTS

Authors declare no competing financial interests.
} 
Since their discovery numerous hiPSCs cell lines from patients with familial diseases have been developed ${ }^{3,4}$. Although iPSCs can differentiate into any type of body cell, they exhibit fetal-like characteristics, remain largely immature, and fail to fully integrate to the host organ upon transplantation ${ }^{5-8}$. This means they are not always suitable for studying diseases that manifest in the adult.

\section{Characteristics of PSC-CMs}

Heart disease supersedes all other causes of death worldwide ${ }^{9}$ and PSC-derived cardiomyocytes (PSC-CMs) offer tremendous opportunities for modeling genetic cardiomyopathies and treatment of heart failure with regenerative therapies ${ }^{4,10}$. However, nearly all cardiomyopathies develop in adult life, and many PSC-CMs do not truly recapitulate adult disease phenotypes, probably due to the immaturity of the cells.

Cardiac maturation initiates during early embryonic life and continues to early adulthood. During this process, CMs become rectangular, multinucleated, elongated and develop more organized sarcomeric structures ${ }^{5,16}$. Additionally, myosin heavy chain subtypes switch and T-tubule sarcolemma structures and intercalated discs to connect CMs are rapidly formed during the early postnatal period to enable functional maturation ${ }^{16,17}$. Analyzing numerous microarray datasets, we demonstrated that even after prolonged culture, PSC-CMs are comparable to late embryonic and neonatal stages ${ }^{7}$. In addition, their functional properties including $\mathrm{Ca}^{+2}$ transients and sarcomere shortening as well morphological characteristics such as size, shape, nucleation and presence of T-tubules are all consistent with immature fetal-like myocytes ${ }^{18,19}$. Finally, we have previously demonstrated that a number of transcription regulators are misregulated in long-term cultured PSC-CMs, which may explain the inability of the cells to mature beyond late embryonic/neonatal stages ${ }^{7}$.

\section{Methods for PSC-CM maturation}

Several groups have recently applied cellular engineering approaches to facilitate differentiation to more mature cardiomyocytes, including electrical stimulation, cell alignment techniques, culturing on different extracellular matrixes or mechanical stretching ${ }^{11-13}$. These approaches have resulted in CMs with more mature structural and functional properties, including increased conduction velocity, improved calcium handling properties etc. Additionally, treatment of PSC-CMs with either glucocorticoids or thyroid hormones promoted their maturation by increasing their size, sarcomere length, improving their contractility etc. ${ }^{14,15}$. Therefore, it appears that microenvironmental factors such as paracrine and endocrine signals, physical and electrical forces, and extracellular matrices might promote the maturation of PSC-CMs. Despite all these efforts, the resulting PSC-CMs partially mature and do not form T-tubules, acquire adult membrane potentials or shorten sarcomeres. Recently Kadota et al. used an in vivo approach by injecting hPSC-CMs in neonatal and adult rats, but the resulting CMs, determined by heart sections, did not exhibit the size and structure of adult $\mathrm{CMs}^{22}$. This might be due to the use of a different cell source, incubation time or analysis. 


\section{Experimental design}

Islet 1 (Isl1) + CPCs are present in neonatal rodent and human hearts. Unlike PSC-CMs in culture, the vast majority of those neonatal CPCs give rise to fully mature CMs over the next few weeks in $v i v \sigma^{5,23,24}$. Interestingly, recent comparative microarray data suggest that the maturation of CMs is regulated similarly in mice and humans ${ }^{25}$. Based on these findings, we explored the potential of the neonatal heart environment to facilitate maturation of CPCs by injecting mouse and human PSC-derived CPCs into neonatal (postnatal day 3-7) rat hearts ${ }^{26}$. To detect the injected cells in the rat hearts, we used fluorescent-labeled CPCs. We injected FACS-isolated mouse CPCs expressing the Isl1-RFP transgene or unsorted human CPCs expressing high percentages of Isl1. We elected to use rats instead of mice due to their larger heart size and the fact that their heart rate is closer to the human heart. To avoid cellular rejection we used immunosuppressed, athymic animals. We sacrificed the rats at various time points and noted that a relatively small percentage $(\sim 1 \%)$ of the transplanted cells engrafted ${ }^{26}$. CPCs had a much higher survival and engraftment rate and, within one month, in vivo-matured PSC-CMs developed the morphological and functional properties of adult CMs including T-tubule staining, $\mathrm{Ca}^{+2}$ transients and sarcomere shortening ${ }^{26}$.

Moreover, their gene expression pattern, based on single cell RNA-sequencing analysis, was similar to adult CMs. It is worth noting that PSC-CMs do not mature properly when they are injected into older rat hearts (after postnatal day 14) ${ }^{26}$. This suggests the presence of a critical neonatal window that allows PSC-CM maturation.

\section{Applications of the neonatal rat system for the generation of adult-like mature cardiomyocytes from pluripotent stem cells}

Our system can be used to further understand the mechanisms of CM maturation as well as to study the pathogenesis of several adult cardiac diseases. Furthermore, rats with transplanted matured hiPSC-CMs can be used for the in vivo testing of drug therapies and for personalized medicine. Importantly, based on the same principal, our protocol may also be utilized for the maturation of other cell types like neurons, hepatocytes, skeletal muscle etc. derived from hiPSCs. In fact, a recent study used the neonatal brain to mature hiPSCderived neurons in vivo for modeling Alzheimer's disease ${ }^{27}$. Finally, considering the late onset of numerous diseases such as certain familial cardiomyopathies and Alzheimer's disease, the neonatal system may be used to uncover the characteristics of cells at the point of disease onset, enabling earlier disease diagnosis, prevention, and better disease management.

\section{Limitations}

The main limitation of our protocol is the low cell engraftment, which is primarily due to the small size of the host heart and our current cell delivery method. However, it is very likely the use of larger animals such as pigs and a higher number of cell injections will markedly improve cellular engraftment and the yield of matured PSC-CMs, which will also potentially allow the in vivo modeling of human diseases in animal models. In addition, the need to generate a genetically modified reporter PSC line in order to locate the injected cells in the host's heart may make our protocol less suitable for the production of mature cardiomyocytes for clinical applications. 


\section{MATERIALS \\ REAGENTS}

Rats

- We used athymic, T-cell deficient RNU (Charles River Laboratories) rats, between postnatal day 1 (P1) to postnatal day 7 (P7) as immunosuppressed hosts of injected cells.

! CAUTION Experiments using rodents must conform to all relevant institutional and governmental ethics regulations. This protocol was approved by the Johns Hopkins University animal care and use committee.

\section{Embryonic Stem Cells}

- We used the mouse ESC reporter line (mESCIsI1-Cre; Rosa-RFP; aMHC-GFP) which we have previously generated ${ }^{28}$ and the human iPSC line 2016 which was provided by Takahashi et al. ${ }^{1}$

! CAUTION The cell lines used in your research should be regularly checked to ensure they are authentic and are not infected with mycoplasma.

- $\quad$ Glasgow's MEM (GMEM) (Gibco, Cat no: 11710035)

- $\quad$ Dulbecco's Modified Eagle's Medium high glucose (DMEM) (Gibco, Cat no: 11965-092)

- Characterized Fetal Bovine Serum (FBS) 500mL (Invitrogen, Cat no: SH30071.03)

- $\quad$ Sodium Pyruvate 100mM (Gibco, Cat no: 11360)

- $\quad \beta$-mercaptoethanol (Sigma, Cat no: M6250)

- $\quad$ ESGRO® (LIF) (Millipore, Cat no: ESG1106)

- $\quad$ PD0325901 (Selleckchem, Cat no: S1036)

- $\quad$ CHIR99021 (Selleck chemicals, Cat no: S2924)

- $\quad 0.1 \%(w / v)$ Gelatin (EMD Millipore, Cat no: ES-006-B)

- $\quad 1 X$ DPBS w/Calcium and Magnesium (Thermo Fisher Scientific, Cat no: 21-031-CV)

- $1 X$ PBS w/o Calcium and Magnesium (Thermo Fisher Scientific, Cat no: 21-040-CV)

- $\quad$ TrypLE (Gibco, Cat no: 12604)

- $\quad$ IMDM (Gibco, Cat no: 12440053)

- Ham's F12 (Gibco, Cat no: 10-080-CV)

- $\quad$ N2-SUPPLEMENT (Gibco, Cat no: 17502-048)

- $\quad$ B27® minus vitamin A (50x) (Thermo Fisher Scientific, Cat no: 12587010) 
- $\quad$ B27® minus insulin (50x) (Thermo Fisher Scientific, Cat no: A1895601)

- $\quad$ Bovine Serum Albumin (BSA) (Sigma, Cat no: A2153)

- $\quad$ 100X Pen/Strep (Gibco, Cat no: 15070-063)

- Monothioglycerol (Sigma, Cat no: M-6145)

- $\quad$ Ascorbic Acid (Sigma, Cat no: A-4544)

- $\quad$ BMP4 (R \& D Systems, Cat no: 314-BP)

- $\quad G^{2}{ }^{2}{ }^{\mathrm{TM}}$ LDEV-Free Reduced Growth Factor Basement Membrane Matrix (ThermoFisher Scientific, Cat no: A1413202)

- $\quad$ Essential 8 Medium (Gibco, Cat no: A1517001)

- $\quad$ RPMI 1640 Medium (Gibco, Cat no: 11875119)

- $\quad$ Y-27632 (ROCK inhibitor) (Stem cell technologies, Cat no: 72304)

- $\quad$ XAV939 (Sigma, Cat no: X3004)

- $\quad$ Isoflurane (Forane) (Baxter)

- $\quad$ Penicillin-streptomycin (Gibco, Cat no: 15070)

- $\quad$ Non-essential amino acid solution (NEAA; Invitrogen, Cat no: 11140-050)

- $\quad$ Pierce ${ }^{\mathrm{TM}}$ 16\% (w/v) Formaldehyde (Thermo Fisher Scientific, Cat no: 28906)

! CAUTION It is a hazardous solution and a cross-linking agent. Wear gloves and a lab coat when handle it. Dispose it appropriately after use.

- $\quad$ GlutaMAX (100 x) (Gibco, Cat no: 35050-061)

- $\quad$ Saponin (Sigma, Cat no: S4521)

- $\quad$ Mouse anti-Islet1 (Developmental Studies Hybridoma Bank, Iowa City, IA)

- $\quad$ Donkey anti-mouse IgG secondary antibody, Alexa Fluor® 647 conjugate (Thermo Fisher Scientific, Cat no: A-31571, Lot \#1757130)

- $\quad$ Sodium Chloride (Sigma, Cat no: S9888)

- $\quad$ Potassium Chloride (Sigma, Cat no: P9333)

- $\quad$ Magnesium Sulfate (Sigma, Cat no: M7506)

- $\quad$ Sodium Phosphate Monobasic (Sigma, Cat no: S3139)

- $\quad$ Sodium Bicarbonate (Sigma, Cat no: S5761)

- $\quad$ Glucose (Sigma, Cat no: D9434)

- $\quad$ HEPES (Sigma, Cat no: H3375)

- $\quad$ Magnesium Chloride (Sigma, Cat no: M8266)

- $\quad$ Calcium Chloride (Sigma, Cat no: C1016) 
- $\quad$ Collagenase type II (Worthington Biochemical Corporation, Cat no: LS004176)

- $\quad$ Protease type XIV (Sigma, Cat no: P5147)

- $\quad$ Fura-2AM (Thermo Fisher Scientific, Cat no: F1221)

- $\quad$ Fluor 594-conjugated WGA antibody (Thermo Fisher Scientific, Cat no: W11262)

- $\quad$ ProLong ${ }^{\circledR}$ Diamond Antifade mount. (Thermo Fisher Scientific, Cat no: P36961)

- $\quad$ RNase inhibitor (Thermo Fisher Scientific, Cat no: N8080119)

- $\quad$ DNase I (RNase free) (New England Biolabs, Cat no: M0303S)

- $\quad$ RNase free water (Qiagen, Cat no: 129112)

- $\quad$ SMARTscribe reverse transcriptase (Clontech, Cat no: 639536)

- $\quad$ dNTP Mix (10mM each) (Thermo Fisher Scientific, Cat no: R0191)

- $\quad$ DTT, 1M (Thermo Fisher Scientific, Cat no: P2325)

- $\quad$ Advantage ${ }^{\circledR} 2$ Polymerase mix (Clontech, Cat no: 639201)

- $\quad$ Custom-designed PCR primers (Integrated DNA Technologies)

- $\quad$ AMPure XP PCR purification kit (Beckman Coulter, Cat no: A63880)

- $\quad$ RPMI 1640 without Glucose (Thermo Fisher Scientific, Cat no 11879020)

- $\quad$ Sodium L-Lactate (Sigma, Cat no: 71718)

- $\quad$ Mouse anti-Isl1 antibody, clone 39.4D5-c (Developmental Studies Hybridoma Bank)

! CRITICAL It is crucial that anti-islet1 antibody from this supplier is used rather than an alternative. We found other anti-islet1 antibodies were not as specific.

\section{EQUIPMENT}

- $\quad$ Cell culture plate, six wells (Corning, Cat no. 3506)

- $\quad$ T25 flasks (Corning, Cat no: 353109)

- $\quad$ Falcon $^{\mathrm{TM}} 15 \mathrm{~mL}$ Conical Centrifuge Tubes (Corning, Cat no: 100150)

- $\quad$ Falcon $^{\mathrm{TM}}$ 50mL Conical Centrifuge Tubes (Corning, Cat no: 100151)

- Cell culture petri dish, $100 \mathrm{~mm} \times 20 \mathrm{~mm}$ (Corning, Cat no: 430293)

- $\quad$ Suspension culture dish $150 \mathrm{~mm} \times 25 \mathrm{~mm}$ (Corning, Cat no: 430597)

- $\quad$ Scepter ${ }^{\mathrm{TM}} 2.0$ Handheld Automated Cell Counter with pack of $60 \mu \mathrm{m}$ Sensors (Millipore, Cat no: PHCC20060)

- $\quad$ Corning Ultra Low Attachment T75 flask (Fisher Scientific, Cat no: 07-200-875) 
- $\quad$ Corning BioCoat ${ }^{\mathrm{TM}}$ Laminin 60mm TC-Treated Culture Dishes (Corning, Cat no: 354405)

- $\quad$ Cell strainer 70 $\mu \mathrm{m}$ (Fisher Scientific, Cat no: 08-771-2)

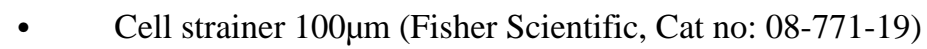

- $5 \mathrm{~mL}$ Polystyrene round-bottom tube with a $40 \mu \mathrm{m}$ cell strainer (BD Falcon, Cat no: 352235)

- $\quad$ Eppendorf® FemtoJet ${ }^{\circledR}$ Microinjector (Eppendorf, Cat no: 10910)

- $\quad \mathrm{CO}_{2}$ Incubator (Thermo Fisher, Cat no: 51030285)

- Cell sorter (Sony SH800 or any other fluorescence-activated cell sorter)

- $\quad$ BD Accuri C6 plus flow cytometer (BD Biosciences)

- $\quad$ EVOS®FL microscope (Thermo Fisher scientific, Cat no: AMF4300)

- $\quad$ Eclipse TE2000 inverted microscope (Nikon)

- $\quad$ Centrifuge Sorvall Legend XT (ThermoFisher, Cat no: 75004508)

- $\quad$ Fine Scissors $2.5 \mathrm{~mm}$ cutting edge (Fine Science Tools, Cat no: 15000-08)

- $\quad$ Ultra-Fine Forceps (Fine Science Tools, Cat no: 11370-40)

- $\quad$ Student Fine Scissors (Fine Science Tools, Cat no: 91460-11)

- $\quad$ Tissue adhesive glue 3M VETBOND (Fisher Scientific, Cat no: NC9259532)

- $\quad$ Mini Rocker (Bio-Rad, Cat no: 166-0710EDU)

- $\quad$ Dissecting stereoscopic microscope Discovery V8 (Zeiss)

- $\quad$ Sure-Seal Large Mouse/Rat Induction Chamber (WPI, cat. no. EZ-1785)

- $\quad$ Stericup 500mL/1000mL Millipore Express ${ }^{\circledR}$ (Millipore, Cat no: SCGPU10RE)

- $\quad$ Stericup 500mL/500mL Millipore Express ${ }^{\circledR}$ (Millipore, Cat no: SCGPU05RE)

- $\quad$ Steriflip ${ }^{\circledR} 50 \mathrm{~mL}$ Disposable Vacuum Filtration System (Millipore, Cat no: SCGP00525)

- $\quad$ IonOptix software (Myocam-S)

- $\quad$ pClamp 10 software (Molecular Devices)

- Image J software Version 1.50e (NIH, http://imagej.nih.gov/ij)

- $\quad$ Confocal microscope (Leica DM2500)

- $\quad 5 \mathrm{~mm}$ round cover glass (Warner instruments, Cat no: W4 64-0700)

- $\quad$ FlowJo software ver. 10.0.8r1

\section{REAGENT SETUP}

2i medium-1L of the medium contains $870 \mathrm{~mL}$ GMEM, $100 \mathrm{~mL}$ FBS, $10 \mathrm{~mL}$ GlutaMAX $^{\mathrm{TM}}, 10 \mathrm{~mL}$ NEM NEAA, $10 \mathrm{~mL}$ Sodium Pyruvate, $3 \mu \mathrm{L}$ beta-mercaptoethanol, 
$20 \mu \mathrm{L}$ of Lif ( $200 \mathrm{U} / \mathrm{mL}$ ), $0.3 \mu \mathrm{M}$ CHIR99021 and $0.1 \mu \mathrm{M}$ PD0325901. Filter to sterilize it using a $1 \mathrm{~L}$ filter and store at $4^{\circ} \mathrm{C}$ for up to one month.

MEF medium $-500 \mathrm{~mL}$ of this medium contain $435 \mathrm{~mL}$ DMEM, $50 \mathrm{~mL}$ fetal bovine serum (FBS), $5 \mathrm{~mL}$ non-essential amino acids, $5 \mathrm{~mL}$ Sodium Pyruvate and $5 \mathrm{~mL}$ of GlutaMAX ${ }^{\mathrm{TM}}$. Filter to sterilize using a $500 \mathrm{~mL}$ filter and store at $4^{\circ} \mathrm{C}$ for up to one month.

SFD medium-1L of this medium contains $715 \mathrm{~mL}$ IMDM, $250 \mathrm{~mL}$ Ham's F12, $5 \mathrm{~mL}$ N2-Supplement $(0.5 \% \mathrm{v} / \mathrm{v}), 10 \mathrm{~mL}$ B27 minus Vitamin A, $5 \mathrm{~mL}$ of $10 \%$ (w/v) BSA (in PBS), $7.5 \mathrm{~mL}$ GlutaMAX ${ }^{\mathrm{TM}}$ and $7.5 \mathrm{~mL}$ Pen-Strep. Filter to sterilize using a $500 \mathrm{~mL}$ filter and store at $4^{\circ} \mathrm{C}$ for up to one month. $\Delta$ CRITICAL To differentiate mESCs, add Ascorbic Acid $(50 \mu \mathrm{g} / \mathrm{mL})$ and $3.9 \times 10^{-3} \%(\mathrm{v} / \mathrm{v})$ of Monothioglycerol (MTG) prior to using.

FACS sorting solution 10X-This solution contains 1\% (v/v) FBS, $200 \mathrm{mM}$ HEPES and $10 \mathrm{mM}$ of EDTA in PBS. Filter to sterilize using a $50 \mathrm{~mL}$ filter and store at $4^{\circ} \mathrm{C}$ for up to two months.

RPMI plus B27 minus insulin medium-Mix 500mL of RPMI 1640 Medium with 10 $\mathrm{mL}$ of $\mathrm{B} 27$ minus insulin and store at $4^{\circ} \mathrm{C}$ for up to two months.

RPMI plus B27 minus Vitamin A medium-Mix 500mL of RPMI 1640 Medium with $10 \mathrm{~mL}$ of $\mathrm{B} 27$ minus Vitamin A and store at $4^{\circ} \mathrm{C}$ for up to two months.

FACS immunostaining solution-This solution contains 5\% (v/v) FBS and $0.75 \%$ $(\mathrm{w} / \mathrm{v})$ of Saponin in PBS. Filter to sterilize using a $50 \mathrm{~mL}$ filter and store at $4^{\circ} \mathrm{C}$ for up to 3 months.

Tyrode's solution 10X-This solution contains $1.37 \mathrm{M} \mathrm{NaCl}, 49 \mathrm{mM} \mathrm{KCl}, 12 \mathrm{mM}$ $\mathrm{MgSO}_{4}, 12 \mathrm{mM} \mathrm{NaH} \mathrm{PO}_{4}, 150 \mathrm{mM}$ Glucose and $200 \mathrm{mM}$ HEPES in distilled water. Store this solution at room temperature $\left(23-27^{\circ} \mathrm{C}\right)$ up to 3 months.

Perfusion buffer 10X-This solution contains $1.2 \mathrm{M} \mathrm{NaCl}, 54 \mathrm{mM} \mathrm{KCl}, 12 \mathrm{mM} \mathrm{MgSO}_{4}$, $10 \mathrm{mM} \mathrm{NaH}_{2} \mathrm{PO}_{4}, 200 \mathrm{mM} \mathrm{NaHCO} 3$ and $56 \mathrm{mM}$ Glucose in distilled water. Filter to sterilize using a $500 \mathrm{~mL}$ filter and keep at room temperature for up to 3 months.

Collagenase solution-Add $50 \mathrm{mg}$ collagenase and $1 \mathrm{mg}$ protease to $50 \mathrm{~mL}$ of $1 \times$ perfusion buffer prior to using and mix well. This solution cannot be stored and needs to be made fresh every time.

\section{PROCEDURE}

\section{Generation of ESC-derived cardiac progenitor cells in vitro}

1. Generate mouse (option A) or human (option B) progenitor cells. 


\section{A Generation of mouse ESC-derived cardiac progenitor cells in vitro TIMING 5 d}

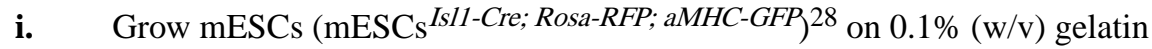
coated T25 flasks in $2 \mathrm{i}$ medium. When cells reach $70-80 \%$ confluence, proceed to the next step to start cell differentiation.

ii. Rinse the cells once with $\mathrm{Ca}^{2+}, \mathrm{Mg}^{2+}$ free DPBS and then dissociate into single cells by adding $1 \mathrm{~mL}$ of TrypLE and incubating at $37^{\circ} \mathrm{C}$ for $3 \mathrm{~min}$.

iii. Inactivate TrypLE by adding $4 \mathrm{~mL}$ of MEF medium. Prepare the cells for counting by diluting the resuspended cells 1:10 in MEF medium and mixing well with a pipette. Attach the $60 \mu \mathrm{m}$ Scepter sensor to the Scepter 2.0 handheld automated cell counter and then aspirate the cells. The total cell number equals the number provided by the automated counter multiplied by 10 times the number of the total mLs.

A CRITICAL STEP $10 \times 10^{6}$ cells are needed for cell differentiation. Use the remaining $\mathrm{mESCs}$ for cell maintenance.

iv. Centrifuge $10 \times 10^{6}$ cells for $3 \mathrm{~min}$ at $270 \mathrm{~g}$, at room temperature. Then aspirate the supernatant and resuspend the cells in $100 \mathrm{~mL}$ of SFD.

v. Split the resuspended cells into four $150 \mathrm{~mm} \times 25 \mathrm{~mm}$ sterile plates and incubate in the $5 \% \mathrm{CO}_{2}$ incubator for 48 hours. The mESCs should form embryoid bodies (EBs) during this 48 hour incubation.

vi. Collect all the EBs in two $50 \mathrm{~mL}$ tubes and centrifuge for $3 \mathrm{~min}$ at $145 \mathrm{~g}$, at room temperature.

A CRITICAL STEP Using a low speed (145 $g$ ) enables isolation of almost exclusively EBs and avoids the precipitation of single cells.

vii. Aspirate the supernatant and resuspend the EBs in $100 \mathrm{~mL}$ of SFD medium, 6 $\mu \mathrm{M}$ of CHIR99021 and $0.4 \mathrm{ng} \mathrm{mL}^{-1}$ of BMP4 for differentiation induction. Split the resuspended EBs into four $150 \mathrm{~mm} \times 25 \mathrm{~mm}$ sterile plates and incubate them in the $5 \% \mathrm{CO}_{2}$ incubator for 24 hours. Collect all the EBs in two $50 \mathrm{~mL}$ tubes and centrifuge at $145 \mathrm{~g}$ for $3 \mathrm{~min}$, room temperature. Aspirate the supernatant and resuspend the EBs in $25 \mathrm{~mL}$ of SFD medium. Transfer the resuspended EBs in an ultra-low attachment $75 \mathrm{~cm}^{2}$ flask and incubate the EBs in $5 \% \mathrm{CO}_{2}$ incubator for 48 hours.

CRITICAL STEP If you wish to also or alternatively mature EBs to mESC-CMs in vitro, centrifuge the $\mathrm{EBs}$ at $145 \mathrm{~g}$ for $3 \mathrm{~min}$, room temperature and resuspend them in SFD medium. Culture cells; beating and aMHC-GFP expression should appear 2 days later. Continue to culture the CMs as EBs by changing the medium every other day or dissociating the EBs as in step A(ii), counting the cells and replating 5-6 $610^{5}$ cells/well in $0.1 \%(w / v)$ gelatin coated $24-w e l l$ plates. The cells will attach to the bottom and should be incubated in the 5\% CO2 incubator for one month, changing the SFD medium every other day. Cells can then be analyzed as described in Box $\mathbf{3}$ 
viii. To dissociate the EBs and collect single CPCs, first centrifuge them at $145 \mathrm{~g}$ for $3 \mathrm{~min}$, room temperature and aspirate the supernatant. Add $1 \mathrm{~mL}$ of TrypLE and incubate at $37^{\circ} \mathrm{C}$ for $3 \mathrm{~min}$. Mix well by pipetting to dissociate the cells.

\section{? TROUBLESHOOTING}

CRITICAL STEP At this time point almost all the EBs should express Isl1-RFP, this can be checked under the microscope (Fig. 2A).

ix. Add $4 \mathrm{~mL}$ of MEF medium to inactivate TrypLE and mix well by pipetting. To remove the non-dissociated EBs, filter the mix using a $70 \mu \mathrm{m}$ strainer and centrifuge the filtrated cells for $3 \mathrm{~min}$ at $270 \mathrm{~g}$, room temperature. Aspirate the supernatant and add $1 \mathrm{~mL}$ of FACS sorting solution to resuspend.

x. To remove all cell clusters prior to sorting, filter the cells once more using a 5 $\mathrm{mL}$ polystyrene round-bottom tube with a $40 \mu \mathrm{m}$ cell strainer. Keep the cells on ice until sorting.

xi. Sort Isl1-RFP positive cells by FACS (Sony SH800) (Fig. 2B, Supplemental Figure 1) and collect the sorted cells in $1 \mathrm{~mL}$ of FBS.

A CRITICAL STEP Avoid long sorting times and keep the FACS sorting solution, the cell sample and sorted cells at low temperatures $\left(\sim 4-5^{\circ} \mathrm{C}\right)$ to decrease the amount of cell death. Injecting unsorted cells can lead to teratoma formation (Supplemental Figure 2)

\section{? TROUBLESHOOTING}

xii. Centrifuge sorted Isl1-RFP positive CPCs for $3 \mathrm{~min}$ at $270 \mathrm{~g}$, room temperature. Aspirate the supernatant and resuspend the cells in IMDM with Geltrex at 60:1 ratio to a final concentration of $2 \times 10^{3}$ cells $\mathrm{mL}^{-1}$. Keep CPCs on ice before transplantation.

$\triangle$ CRITICAL STEP To avoid the polymerization of Geltrex which will increase the viscosity of the cell sample and will clog the microneedle during cell injection, keep the sample on ice at all times for no more than 4 hours.

PAUSEPOINT

\section{B Generation of human iPSC-derived cardiac progenitor cells in vitro TIMING 5-6 d}

i. Generate a constitutively expressing GFP/RFP, hiPSC line (Box 1). Grow hiPSCs on Geltrex coated T25 flasks using Essential 8 medium until they reach 70-80\% confluence (this usually occurs after 3-4 days), at which point you should proceed to the next step to start cell differentiation.

A CRITICAL STEP Coat each T25 flask with $3 \mathrm{~mL}$ of 1:60 Geltrex in DMEM, for 30-120 min, room temperature. Determine how many T25 flasks are needed based on the desired cell number. Each T25 flask when 70-80\% confluent contains approximately $3-4 \times 10^{6}$ cells. 
ii. Coat at least 2 wells of a 6-well plate with Geltrex in DMEM (1:60) using $2 \mathrm{~mL}$ per well

iii. Rinse the cells from step B(i) once with $\mathrm{Ca}^{2+}, \mathrm{Mg}^{2+}$ free DPBS and then dissociate into single cells by adding $1 \mathrm{~mL}$ of TrypLE and incubating at $37^{\circ} \mathrm{C}$ for $3 \mathrm{~min}$.

iv. Inactivate TrypLE by adding $4 \mathrm{~mL}$ of MEF medium. Prepare the cells for counting by diluting the resuspended cells 1:10 in MEF medium and mixing well with a pipette. Attach the $60 \mu \mathrm{m}$ Scepter sensor to the Scepter 2.0 handheld automated cell counter and then aspirate the cells. The total cell number equals the number provided by the automated counter multiplied by 10 times the number of the total mLs.

$\triangle$ CRITICAL STEP $3 \times 10^{6}$ cells are needed for cell differentiation.

v. Centrifuge $3 \times 10^{6}$ hiPSCs for $3 \mathrm{~min}$ at $270 \mathrm{~g}$, room temperature.

$\triangle$ CRITICAL STEP For cell maintenance keep 3-6 $\times 10^{5}$ hiPSCs and replate them in a T25 flask.

vi. Aspirate the supernatant and resuspend the cells you are differentiating in Essential 8 medium with $10 \mu \mathrm{M}$ of Rock inhibitor (Y27632) at a concentration of $6 \times 10^{5} \mathrm{hiPSCs} / \mathrm{mL}$ and plate $2.5 \mathrm{~mL}$ per well of a 6 -well plate.

A CRITICAL STEP $100 \%$ confluence is critical for efficient CM differentiation. Therefore, after adding the cells, tap the plate from all sides and leave it inside the hood at room temperature for approximately $15 \mathrm{~min}$. This will enable more homogenous plating of the cells.

vii. To initiate cell differentiation the next day, change the medium to RPMI plus B27 minus insulin and $6 \mu \mathrm{M}$ of CHIR99021 and incubate in the $5 \% \mathrm{CO}_{2}$ incubator for 48 hours.

$\triangle$ CRITICAL STEP To maintain consistency and increase differentiation efficiency, all incubation times stated in this procedure should remain unchanged. In addition, the media should always be added slowly to avoid mechanical stress, which can affect cell differentiation. Use $2.5 \mathrm{~mL}$ of medium per well.

viii. Change the medium to RPMI plus B27 minus insulin and incubate in the 5\% $\mathrm{CO}_{2}$ incubator for 24 hours.

ix. Change the medium to RPMI plus B27 minus insulin and $10 \mu \mathrm{M}$ of XAV939 and incubate in the $5 \% \mathrm{CO}_{2}$ incubator for 48 hours.

CRITICAL STEP If you wish to continue to grow cells in culture rather than proceed to transplantation, change the medium of the cells to RPMI plus B27 minus insulin and incubate in the 5\% CO2 incubator for a further 48 hours. Then change the medium to RPMI plus B27 without Vitamin A and incubate in the 5\% $\mathrm{CO} 2$ incubator for 48 hours. At this stage, most cells will be contracting CMs. Cells can be cultured for one month, during which time continue changing the 
medium to RPMI plus B27 without Vitamin A every other day. Cells can then be analyzed as described in Box 3.

\section{? TROUBLESHOOTING}

x. The majority of the cells at this stage should express Is11. To test the percentage of Isl1+ CPCs, perform immunofluorescent staining and flow cytometry of CPCs Box2 (Fig. 2C).

$\triangle$ CRITICAL STEP To improve the yield of mature CMs, proceed to CPC injection only if approximately more than $60-70 \%$ of CPCs are Isl1+.

Alternatively, fresh cardiomyocytes appearing at days 8-9 may be used with the caveat that their engraftment and survival would be significantly lower in comparison to cardiac progenitor cells.

\section{? TROUBLESHOOTING}

xi. Add $500 \mu \mathrm{L}$ of TrypLE per well to dissociate the cells and incubate at $37^{\circ} \mathrm{C}$ for $3 \mathrm{~min}$. Pipet and mix the cells gently for approximately $30 \mathrm{sec}$, to mechanically dissociate the CPCs and generate single cells. Then add $2 \mathrm{~mL}$ of MEF medium per well, mix and transfer all the cells to a $15 \mathrm{~mL}$ tube. Count the cells as above and centrifuge the CPCs for $3 \mathrm{~min}$ at $270 \mathrm{~g}$, room temperature.

xii. Aspirate the supernatant and resuspend the cells in cold $\left(4^{\circ} \mathrm{C}\right) \mathrm{IMDM}$ with Geltrex at 60:1 ratio and $10 \mu \mathrm{M}$ of Rock inhibitor (Y27632). The cell concentration should be $2 \times 10^{3}$ cells $\mathrm{mL}^{-1}$.

PAUSEPOINT Keep CPCs on ice prior to transplantation for a maximum of 4 hours.

\section{Box 2 Immunofluorescence staining of fixed cells for flow cytometry from step $B(x)$ TIMING 2-2.5 h}

1. Centrifuge the cell mix for $3 \mathrm{~min}$ at $270 \mathrm{~g}$, room temperature. Aspirate the supernatant and resuspend the cells in 4\% (w/v) paraformaldehyde in PBS. Incubate for $30 \mathrm{~min}$, room temperature to fix the cells.

2. Centrifuge the cell mix for 3 min at $895 \mathrm{~g}$, room temperature. Aspirate the supernatant and resuspend the cells in PBS to wash the PFA. Repeat this step once more.

3. Aspirate the supernatant and resuspend the cells in FACS immunostaining solution. Split the sample in two and add mouse anti-Isl1 antibody (1:500 dilution) in one sample and use the other one as negative control. Incubate for 30 min, room temperature.

4. Wash the cells twice as described in step 2 using FACS immunostaining solution instead of PBS. Aspirate the supernatant and resuspend both cell samples in FACS immunostaining solution with 1:500 donkey anti-mouse IgG $(\mathrm{H}+\mathrm{L})$ secondary antibody, Alexa Fluor 647 conjugate. Incubate for $30 \mathrm{~min}$, room temperature. 
5. Wash twice with FACS immunostaining solution as in step E(ii). Aspirate the supernatant and resuspend the cells in PBS. Use the BD Accuri C6 plus flow cytometer to analyze the cells (Fig. 2c, Supplemental Figure 1).

$\triangle$ CRITICAL STEP Use an anti-mouse secondary antibody with high excitation and emission wavelengths to avoid non-specific separation of the GFPtagged CPCs.

\section{Surgery $\bigcirc$ TIMING 7-15 min per rat pup}

A CRITICAL Prior to rat surgery, autoclave all surgical tools.

2 To anesthetize the rat pups wrap in foil and place them on an ice bed (Fig. 3A). Pups should be anesthetized on the ice bed within 5-10 min.

$\triangle$ CRITICAL STEP Take one rat pup at a time and use only postnatal day 1-7 rats. Direct contact of pups with ice is associated with higher post-procedure mortality, therefore keep pups covered with aluminum foil.

A CRITICAL STEP Hypothermia minimizes blood loss during heart surgery and reduces the pup's heart rate allowing for better cell engraftment.

$\triangle$ CRITICAL STEP The time to reach anesthesia varies and depends greatly on the age and weight of the pups. Usually $5 \mathrm{~min}$ is enough for P1 (5-7 g) rat pups, however for P7 (11-13 g) pups longer times up to $10 \mathrm{~min}$ are usually needed.

\section{? TROUBLESHOOTING}

3 Transfer the pup from the ice bed to the surgical bed. Put the rat pup in the supine position and tape all 4 limbs for immobilization. To sterilize the skin and prevent infections, wipe the chest with a Betadine swap.

A CRITICAL STEP For longer anesthesia during surgery, consider cooling the surgical bed using ice or ice packs.

4 Use the fine scissors ( $2.5 \mathrm{~mm}$ cutting edge) to make an incision of approximately 5-6 mm in the skin of the left upper chest wall, between the third and fourth ribs (Fig. 3B). Gently separate the skin from the underlying muscles using fine forceps. Dissect the muscles of the intercostal space and create an opening of approximately 4-5 mm using the forceps (Fig. 3B).

5 Visualize the left ventricular apex and proceed immediately to cell transplantation (Fig. 3C).

$\triangle$ CRITICAL STEP At this stage the skin and muscles of the chest wall are thin and the heart can usually be located. Entering the anterior mediastinum will require very gentle manipulations and practice to avoid injuring any of the major blood vessels.

$\triangle$ CRITICAL STEP Although a wider skin incision can help visualize the heart better, it will decrease the survival of the pup.

\section{? TROUBLESHOOTING}




\section{Cell transplantation and recovery 0 TIMING 10-20 min per rat pup}

6 Load immediately $10 \mu \mathrm{L}$ of the CPC mix into the glass needle and inject all $10 \mu \mathrm{L}$ into the left ventricular apex using the Eppendorf FemtoJet Microinjector.

$\triangle$ CRITICAL STEP Use the coarse mode of Eppendorf FemtoJet Microinjector for faster manipulations and overall quicker injections.

A CRITICAL STEP To avoid penetrating the ventricular wall and improve the pup survival and cell engraftment, do not advance the needle deep in the ventricular wall. Stop advancing after feeling resistance.

7 After the cell injection, pinch the edges of the chest wall incision with the forceps for $10 \mathrm{sec}$ and then use no more than $5 \mu \mathrm{L}$ of the tissue adhesive glue to seal it (Figure 3D).

A CRITICAL STEP Higher amounts of tissue glue can be toxic to the pup or can increase the probability of cannibalization by the mother not recognizing her own pups.

8 Transfer the pup immediately to a heating pad for $10-15 \mathrm{~min}$ and then return to the mother.

$\triangle$ CRITICAL STEP Ensure the pup is fully rewarmed and active prior to return to its mother's cage. Additionally, rub the pup with cage bedding prior to return to its mother to improve survival.

$\triangle$ CRITICAL STEP Since prolonged hypothermia increases pup mortality, surgery should be completed within 5-10 min.

\section{? TROUBLESHOOTING}

\section{Isolation of transplanted cardiomyocytes from injected rat heart $\bullet$ TIMING 1-1.5 $\mathrm{h}$ per heart, $30 \mathrm{~d}$ after cell injection}

9 Transfer the 1 month-old injected rat to the anesthesia induction chamber and euthanize it by adding isoflurane for $3 \mathrm{~min}$.

10 Quickly remove the heart and place it in perfusion buffer ${ }^{29}$. Cannulate the heart via the aorta and use a Langendorff system to perfuse the heart with perfusion buffer for $3 \mathrm{~min}$ at $35-37^{\circ} \mathrm{C}$ at a flow of $10 \mathrm{~mL} \mathrm{~min}^{-1}$. Then perfuse for $15 \mathrm{~min}$ using the collagenase solution at a flow of $\sim 3 \mathrm{~mL} \mathrm{~min}{ }^{-1}$. Within 2 min into this perfusion add $50 \mu \mathrm{M}$ of $\mathrm{CaCl}_{2}$.

$\triangle$ CRITICAL STEP Decrease the perfusion flow to $2-3 \mathrm{~mL} \mathrm{~min}^{-1}$ during collagenase treatment and then increase to $10 \mathrm{~mL} \mathrm{~min}^{-1}$ immediately after.

11 Localize the area of transplanted cells by the presence of an obvious myocardial scar or by visualization of the heart under a fluorescence stereoscopic microscope (Fig. 4A). Cut the transplanted area using scissors (Student Fine Scissors) and transfer it into a small plastic container, which contains $5 \mathrm{~mL}$ of the collagenase solution and cut it to smaller pieces (approximately 20 times). 
12 Add $45 \mathrm{~mL}$ of collagenase solution and mix gently up to 10 times using a plastic pipette. Transfer $35 \mathrm{~mL}$ of supernatant into a $50 \mathrm{~mL}$ tube.

13 Centrifuge the supernatant at $46 \mathrm{~g}$ for $1 \mathrm{~min}$, room temperature. Transfer $30 \mathrm{~mL}$ of the supernatant into the small plastic container with the rest of the heart pieces from step (iv). Keep the pellet.

14 Place the container on the Rocker at low speed for $1 \mathrm{~min}$, room temperature.

15 Transfer the mix to a new $50 \mathrm{~mL}$ tube and centrifuge at $46 \mathrm{~g}$ for $1 \mathrm{~min}$, room temperature.

$\triangle$ CRITICAL STEP To remove the non-dissociated pieces of heart tissue, filter the mix using a $100 \mu \mathrm{m}$ cell strainer.

16 Remove the supernatant and add $10 \mathrm{~mL}$ of Tyrode's solution buffer with $1 \%(\mathrm{w} / \mathrm{v})$ BSA (in PBS) and $250 \mu \mathrm{M}$ of $\mathrm{CaCl}_{2}$ and gently invert to resuspend the $\mathrm{CM}$ pellet.

17 Add $10 \mathrm{~mL}$ of Tyrode's solution with $0.5 \%$ (w/v) BSA (in PBS) to the pellet in the $50 \mathrm{~mL}$ tube from step v. Invert gently to resuspend the CMs.

18 Combine the two mixes from step (vi) and (vii), gently invert to mix and centrifuge for $1 \mathrm{~min}$ at $46 \mathrm{~g}$, room temperature. Cells cannot be stored and will need to be analyzed immediately after this step. (Fig. 4B)

\section{Analysis of transplanted cardiomyocytes from injected rat heart $\bullet$ TIMING 1.5-5 $\mathrm{h}$ per heart}

19 Transplanted cardiomyocytes can be analyzed in various ways. To assess sarcomere shortening and calcium transients, follow option A. To fix cells for Ttubule or other analysis, follow option B. For cDNA generation for single cell gene expression analysis, follow option C.

\section{(A) Sarcomere shortening and Calcium transients}

i. Aspirate the supernatant and add $10 \mathrm{~mL}$ of Tyrode's solution with $250 \mu \mathrm{M}$ of $\mathrm{CaCl}_{2}$ and invert gently to resuspend the CM pellet. Leave the tube upright for $10 \mathrm{~min}$ at room temperature to let the CMs sink to the bottom. Remove the supernatant and add $10 \mathrm{~mL}$ of Tyrode's solution with $500 \mu \mathrm{M}$ of $\mathrm{CaCl}_{2}$.

ii. Repeat the previous step, but add $10 \mathrm{~mL}$ of Tyrode's solution with $1 \mathrm{mM}$ of $\mathrm{CaCl}_{2}$.

iii. Aspirate the supernatant and add $15 \mathrm{~mL}$ of Tyrode's solution with $1 \mathrm{mM}$ of $\mathrm{CaCl}_{2}$ containing $1 \mu \mathrm{M}$ of the ratiometric $\mathrm{Ca}^{2+}$ indicator dye Fura-2AM and incubate for $10 \mathrm{~min}$, room temperature.

iv. Transfer the cells to a heated (at $37^{\circ} \mathrm{C}$ ) perfusion chamber placed on the stage of an inverted microscope. Perfuse the CMs with Tyrode's solution with $1 \mathrm{mM}$ of $\mathrm{CaCl}_{2}$ at a flow-through rate of $2 \mathrm{~mL} \mathrm{~min}^{-1}$. Stimulate the cells at $0.5 \mathrm{~Hz}$ with electrical pulses from two electrodes placed in the perfusion chamber. 
v. Record CM shortening by video-edge detection using the IonOptix software. Use the same software for data analysis.

vi. Record intracellular Fluo-3 fluorescence for $\mathrm{Ca}^{+2}$ transients and analyze the recorded data using pClamp 10 software ${ }^{29,30}$.

\section{(B) Cell fixation for T-tubule staining and analysis}

i. Plate isolated CMs in Tyrode's solution with $1 \mathrm{mM}$ of $\mathrm{CaCl}_{2}$ on a Laminin coated $60 \mathrm{~mm}$ dish and incubate in $5 \% \mathrm{CO}_{2}$ incubator at $37^{\circ} \mathrm{C}$ for $30 \mathrm{~min}$ to let them attach to the dish.

ii. Aspirate Tyrode's solution and add $3 \mathrm{~mL}$ of $4 \%(\mathrm{w} / \mathrm{v})$ paraformaldehyde in PBS and incubate for $20 \mathrm{~min}$ at room temperature for cell fixation. Wash paraformaldehyde twice with PBS. The cells can now be used for immunostaining and nucleation assessment with DAPI staining.

$\triangle$ CRITICAL STEP For confocal microscopy analysis plate the cells on Laminin coated coverslips.

PAUSEPOINT The cells can be stained immediately or after overnight storage at $4^{\circ} \mathrm{C}$.

iii. Block the fixed cells with 1\% (w/v) BSA in PBS by incubating for 1 hour at room temperature. For T-tubule staining, add Fluor 594-conjugated WGA antibody at 1:1000 dilution and incubate at $4^{\circ} \mathrm{C}$ overnight. Wash the cells twice for 5 min with PBS.

A CRITICAL STEP Avoid shorter incubation times to prevent low intensity of the staining.

$\triangle$ CRITICAL STEP Alternative antibody combinations can be substituted, and a standard immunofluorescence staining performed.

iv. Add DAPI to stain the nuclei and incubate for $10 \mathrm{~min}$ at room temperature.

v. Wash the cells twice for 5 minutes with PBS and mount the cells with ProLong Diamond Antifade mount.

PAUSEPOINT The cells can either be imaged immediately or stored overnight at $4^{\circ} \mathrm{C}$ and imaged the next day.

vi. Image the T-tubules using a confocal microscope with a 403 (1.15 NA) oilimmersion lens.

vii. Analyze WGA staining using ImageJ. Apply a median filter, create a binary mask of the WGA signal using the plugin Auto Local Threshold and erode the mask once.

viii. Create a region of interest in each cell. Exclude the boundary membrane to isolate the T-tubule network for segmentation analysis.

ix. Use the Analyze Particles plugin to measure the T-tubule area $\left(\mathrm{mm}^{2}\right)$, which is normalized to the total cell area to calculate the fractional area. 
$\triangle$ CRITICAL STEP Compare two groups using two-tailed t-test. Use the same optical field for statistical comparisons between host CMs and in vivo matured CMs to eliminate staining errors.

\section{(C) cDNA generation for single cell gene expression analysis}

i. Use a $20 \mu \mathrm{L}$ pipette to manually pick the isolated GFP/RFP positive CMs (in Tyrode's solution) under a fluorescent microscope (EVOS). Transfer each cell into a single well of a 96 well plate containing $2.4 \mu \mathrm{L}$ RNase-free water, $0.2 \mu \mathrm{L}$ RNase-free DNase I and $0.25 \mu \mathrm{L}$ RNase inhibitor.

ii. Incubate at $72^{\circ} \mathrm{C}$ for $3 \mathrm{~min}$ to inactivate DNase I and then quench on ice. Add 1 $\mu \mathrm{L}$ of custom-designed primer (with $30 \mathrm{dT}$ anchor) and transfer to $72^{\circ} \mathrm{C}$ for 2 min to anneal to polyadenylated RNA and then quench on ice.

iii. Add a mixture of $1 \mu \mathrm{L}$ SMARTscribe reverse transcriptase, $1 \mu \mathrm{L}$ of customdesigned TSO oligo (12 mM), $0.3 \mu \mathrm{L} \mathrm{MgCl}_{2}(200 \mathrm{mM}), 0.5 \mu \mathrm{L}$ RNase inhibitor, $1 \mu \mathrm{L}$ dNTP mix, $0.25 \mu \mathrm{L}$ DTT $(100 \mathrm{mM})$ and incubate at $42^{\circ} \mathrm{C}$ for $90 \mathrm{~min}$, followed by enzyme inactivation at $70^{\circ} \mathrm{C}$ for $10 \mathrm{~min}$.

iv. Add a mixture of $29 \mu \mathrm{L}$ water, $5 \mu \mathrm{L}$ Advantage 2 taq polymerase buffer, $2 \mu \mathrm{L}$ dNTPs, $2 \mu \mathrm{L}$ custom-designed amplifying PCR primer $(12 \mathrm{mM})$ and $2 \mu \mathrm{L}$ of Advantage 2 taq polymerase to the reverse transcription product and amplify for 20 cycles.

v. Purify the amplification product using Ampure XP beads. Use the cDNA to test gene expression by qPCR or perform RNA sequencing based on previously published protocols ${ }^{26,31}$.

\section{Box 3 Analysis of in vitro matured PSC-derived cardiomyocytes 9 TIMING 1.5-24 h per heart, $30 \mathrm{~d}$ after cell culture}

1. Various methods can be used to analyse the cells. Follow option A for immunostaining and nucleation analysis, option $\mathrm{B}$ for a further in vitro cell culture and option $\mathrm{C}$ for sorting.

\section{(A) Immunostaining and nucleation analysis}

i. Fix in vitro plated PSC-CMs directly with $4 \% \mathrm{w} / \mathrm{v}$ paraformaldehyde in PBS for $30 \mathrm{~min}$ and use for immunostaining and nucleation analysis (DAPI staining).

ii. Wash the fixed cells twice for 5 min with PBS at room temperature.

iii. Stain for 5 min with DAPI (1:2000) in PBS followed by two washings for $5 \mathrm{~min}$ with PBS at room temperature. Keep the cells in PBS and either store overnight at $4^{\circ} \mathrm{C}$ or image immediately.

iv. Save images and manually count and analyze the number of nuclei per cell. 


\section{(B) Further culture of cells}

i. Replate the cells by dissociating with TrypLE (as described in step1 A(ii) and (iii)) and replating on gelatin coated $5 \mathrm{~mm}$ round cover glass in either SFD medium for mouse CMs or RPMI plus B27 minus Vitamin A with 10\% FBS and $10 \mu \mathrm{M}$ of Rock inhibitor for human CMs to increase cell survival.

ii. Transfer the cover glass with plated CMs into the perfusion chamber just before measuring $\mathrm{Ca}^{+2}$ transients and sarcomere shortening.

iii. Measure whole-cell $\mathrm{Ca}^{+2}$ transients and sarcomere shortening as described in step 19A.

\section{(C) Sorting of cells}

i. Sort cells as single cells using a cell sorter or pick single cells directly under microscope (EVOS) and transfer them to 96-well plate for cDNA preparation as above.

\section{Box 1 - Generation of GFP/RFP-tagged human iPSCs $\odot$ TIMING 3 w ADDITIONAL MATERIALS \\ REAGENTS}

\section{Lentivirus}

- We used a CAG-GFP lentivirus (Cellomics Technology, Cat no: PLV-10057-50). Alternatively, a CAR-RFP lentivirus can also be used (Cellomics Technology, Cat no: PLV-10071-50)

! CAUTION The handling of lentiviral vectors should be carried out using the proper biosafety containment. See Guidance on Biosafety Considerations for Research with Lentiviral Vectors (http://osp.od.nih.gov/sites/default/files/ resources/Lenti_Containment_Guidance.pdf)

- $\quad$ DMSO (Corning Cellgro, Cat no: 25-950-CQC)

\section{EQUIPMENT}

- Cryogenic vials (Corning, Cat no: CLS431421)

1 Coat with Geltrex 3 wells of a 6-well plate as described in step 1B(i). Dissociate plated hiPSCs as described in steps $1 \mathrm{~A}(\mathrm{ii})$ and $1 \mathrm{~A}(\mathrm{iii})$. Resuspend $6 \times 10^{5}$ cells in 6 $\mathrm{mL}$ of Essential 8 medium with $10 \mu \mathrm{M}$ of Rock inhibitor and split them in three 15 $\mathrm{mL}$ tubes. Quickly thaw one vial of the CAG-GFP/RFP lentivirus and test three different volumes by adding 2,5 and $10 \mu \mathrm{L}$ to determine the optimal transduction efficiency of the virus. Mix well and plate the infected hiPSCs in the wells. Incubate in the $5 \% \mathrm{CO}_{2}$ incubator overnight.

$\triangle$ CRITICAL STEP Split the rest of the virus in $2 \mu \mathrm{L}$ aliquots and store in $-80^{\circ} \mathrm{C}$ to avoid thaw and refreeze which will decrease the transduction efficiency of the virus. Use bleach to clean all equipment that is in contact with the virus. 
2 The next morning change the medium to Essential 8 to avoid cell toxicity. Then over the next days, change the medium to Essential 8 daily and determine the transduction efficiency using a fluorescent microscope to check GFP/RFP expression. When cells reach 60-70\% confluence, dissociate the cells in the well with the highest GFP/RFP expression and replate $\sim 5 \times 10^{4}$ cells in two Geltrex coated sterile $10 \mathrm{~cm}$ petri dishes (in Essential 8 with $10 \mu \mathrm{M}$ of Rock inhibitor).

3 Continue to change Essential 8 medium daily and then 2-3 days later single cells will form colonies. Pick single GFP/RFP-only colonies using a $20 \mu \mathrm{L}$ pipette under a fluorescent microscope in a cell culture hood. Transfer colonies in Geltrex coated wells of a 24-well plate containing Essential 8, $10 \mu \mathrm{M}$ of Rock inhibitor and Penicillin-streptomycin.

4 Grow the cells for 3-4 days and then replate only the colonies where all cells have GFP/RFP expression. Replate each colony to a new well of 6-well plate and then subsequently expand the cells by growing them in a T25 flask.

5 When GFP-tagged hiPSCs reach 70-80\% confluence split them in 4 cryovials with $10 \%$ DMSO in MEF medium and freeze them in $-80^{\circ} \mathrm{C}$ for two days and then store them in liquid nitrogen.

A CRITICAL STEP To improve the survival of the colonies picked in step 3, keep the cells in the same Essential 8 medium with Rock inhibitor for 48 hours.

PAUSEPOINT Cells can be stored in liquid nitrogen for at least 10 years.

6 To thaw the cells, prepare $4 \mathrm{~mL}$ of prewarmed at $37^{\circ} \mathrm{C}$ MEF medium in a $15 \mathrm{~mL}$ tube. Quickly thaw the frozen cells by moving the cryovial from liquid nitrogen directly to a $37^{\circ} \mathrm{C}$ water bath and before the cells are completely thaw add $1 \mathrm{~mL}$ of the prewarmed MEF medium directly to the cells in the cryovial. Mix well with the rest of the MEF medium in the $15 \mathrm{~mL}$ tube. Centrifuge for $3 \mathrm{~min}$ at $270 \mathrm{~g}$, room temperature. Aspirate the supernatant and resuspend the cells in Essential 8 medium with $10 \mu \mathrm{M}$ of Rock inhibitor (Y27632) and replate them in a T25 flask coated with matrigel as in step 1(B)i.

\section{? TROUBLESHOOTING}

\begin{tabular}{lll}
\hline Step & Problem & Solution \\
\hline 1A(viii) & $\begin{array}{l}\text { Usually 25-35\% of the cells will } \\
\text { be positive for Isl1 but } \\
\text { occassionaly the percentage of } \\
\text { Isl1-RFP cells is less than 10\% }\end{array}$ & $\begin{array}{l}\text { Incubate the EBs for 12-24 hours longer to increase the } \\
\text { percentage of isl1+ cells }\end{array}$ \\
\hline 1A(xi) & $\begin{array}{l}\text { High percentsge of sorted dead } \\
\text { cells }\end{array}$ & $\begin{array}{l}\text { Add DAPI to FACS sorting solution (dilution 1:2000) to stain } \\
\text { and exclude dead cells. In addition, to improve cell survival, } \\
\text { consider adding 10mM Rock inhibitor to the FACS sorting } \\
\text { solution }\end{array}$ \\
\hline B(ix) & Low percentage of hiPSC-CMs & $\begin{array}{l}\text { Incubate the cells at day 9, in RPMI without glucose and 5 } \\
\text { mM of sodium lactate. Change the medium every other day } \\
\text { for a maximum of 4 days. Then continue culturing the cells in } \\
\text { RPMI-B27 without Vitamin A. }\end{array}$ \\
\hline
\end{tabular}




\begin{tabular}{cll} 
B(x) & $\begin{array}{l}\text { Low percentage of isl1+ human } \\
\text { CPCs }\end{array}$ & $\begin{array}{l}\text { optimize the cell differentiation protocol by testing different } \\
\text { concentrations of CHIR99021 (up to 10mM depending on the } \\
\text { hiPSC line) and XAV939. Additionally, try analyzing CPCs } \\
12-24 \text { hours later. }\end{array}$ \\
\hline 2 & $\begin{array}{l}\text { Increased post-procedure } \\
\text { mortality due to prolonged } \\
\text { hypothermia }\end{array}$ & Monitor closely the pups while they are on ice. \\
\hline 5 & $\begin{array}{l}\text { Pups develop bleeding during } \\
\text { surgery }\end{array}$ & $\begin{array}{l}\text { Use hypothermia during surgery and fine forceps with blunt } \\
\text { ends. }\end{array}$ \\
\hline 8 & $\begin{array}{l}\text { CPCs do not engraft or the final } \\
\text { number of cells is low, }\end{array}$ & $\begin{array}{l}\text { Use a previously published prosurvival cocktail } \\
\text { the engraftment and survival of the transplanted cells }\end{array}$ \\
\hline
\end{tabular}

\section{- TIMING}

Steps A(i)-(xii), Generation of mouse ESC-derived cardiac progenitor cells in vitro: 5 d

Steps B(i)-(xii), Generation of mouse ESC-derived cardiac progenitor cells in vitro: $5-6 \mathrm{~d}$

Steps 2-5, Surgery: 7-15 min per rat pup

Steps 6-8, Cell transplantation and recovery: 10-20 min per rat pup

Steps 9-18, Isolation of transplanted cardiomyocytes from injected rat heart: 1-1.5 $\mathrm{h}$ per heart, one month after cell injection

Step 19 Analysis of transplanted cardiomyocytes from injected rat heart: $1.5-5 \mathrm{~h}$ per heart

Box 1, Generation of GFP/RFP-tagged human iPSCs: $3 \mathrm{w}$

Box 2 Immunofluorescence staining of fixed cells for flow cytometry: 2-2.5 h

Box 3, Analysis of in vitro matured PSC-derived cardiomyocytes: 1.5-24 h per heart, $30 \mathrm{~d}$ after cell culture

\section{ANTICIPATED RESULTS}

This protocol describes a method to generate mature, adult-like mouse or human PSC-CMs, using neonatal immunosuppressed rats as a live bioincubator. It takes advantage of the environmental cues of a neonatal heart to advance $\mathrm{CM}$ development, which is otherwise blocked, during their in vitro growth, at late embryonic stages.

After one month of CPC transplantation, isolated mouse or human PSC-CMs should acquire the morphologic and functional characteristics of an adult CM (Fig. 5). Those cells can be compared with in vitro matured CMs. We have not observed any teratomas after the injection of highly enriched CPCs. Importantly, as we have demonstrated, in vivo matured hiPSCs can recapitulate adult cardiomyopathies and can expedite the modeling of diseases that are otherwise challenging to study in vitro ${ }^{26}$. The resulting human-rat chimeras can potentially be used for in vivo drug testing, bringing us a step closer to personalized medicine. 
More examples of typical morphologic results can be found in Figure 1 of the ref. 23. Examples of the functional properties of in vivo matured PSC-CMs can be found in Figures 2 and 4 of the ref. 23.

\section{Supplementary Material}

Refer to Web version on PubMed Central for supplementary material.

\section{Acknowledgments}

The authors thank Kwon laboratory members for critical reading and discussions. E.T. was supported by Johns Hopkins School of Medicine Clinician Scientist Award. This work was supported by the Magic that Matters Fund, MSCRF (2015-MSCRFI-1622), NHLBI/NIH (R01HL111198), and NICHD/NIH (R01HD086026) to C.K.

\section{References}

1. Takahashi K, et al. Induction of pluripotent stem cells from adult human fibroblasts by defined factors. Cell. 2007; 131:861-872. DOI: 10.1016/j.cell.2007.11.019 [PubMed: 18035408]

2. Burridge PW, Keller G, Gold JD, Wu JC. Production of de novo cardiomyocytes: human pluripotent stem cell differentiation and direct reprogramming. Cell stem cell. 2012; 10:16-28. S1934-5909(11)00594-7 [pii]. DOI: 10.1016/j.stem.2011.12.013 [PubMed: 22226352]

3. Bellin M, Marchetto MC, Gage FH, Mummery CL. Induced pluripotent stem cells: the new patient? Nat Rev Mol Cell Biol. 2012; 13:713-726. nrm3448 [pii]. DOI: 10.1038/nrm3448 [PubMed: 23034453]

4. Moretti A, Laugwitz KL, Dorn T, Sinnecker D, Mummery C. Pluripotent stem cell models of human heart disease. Cold Spring Harbor perspectives in medicine. 2013; 3

5. Yang X, Pabon L, Murry CE. Engineering adolescence: maturation of human pluripotent stem cellderived cardiomyocytes. Circulation research. 2014; 114:511-523. CIRCRESAHA.114.300558 [pii]. DOI: 10.1161/CIRCRESAHA.114.300558 [PubMed: 24481842]

6. Tabar V, Studer L. Pluripotent stem cells in regenerative medicine: challenges and recent progress. Nature reviews Genetics. 2014; 15:82-92. DOI: 10.1038/nrg3563

7. Uosaki H, et al. Transcriptional Landscape of Cardiomyocyte Maturation. Cell reports. 2015; 13:1705-1716. DOI: 10.1016/j.celrep.2015.10.032 [PubMed: 26586429]

8. Cho GS, Fernandez L, Kwon C. Regenerative medicine for the heart: perspectives on stem-cell therapy. Antioxidants \& redox signaling. 2014; 21:2018-2031. DOI: 10.1089/ars.2014.6063 [PubMed: 25133793]

9. Finegold JA, Asaria P, Francis DP. Mortality from ischaemic heart disease by country, region, and age: statistics from World Health Organisation and United Nations. International journal of cardiology. 2013; 168:934-945. DOI: 10.1016/j.ijcard.2012.10.046 [PubMed: 23218570]

10. Yoshida Y, Yamanaka S. iPS cells: a source of cardiac regeneration. Journal of molecular and cellular cardiology. 2011; 50:327-332. DOI: 10.1016/j.yjmcc.2010.10.026 [PubMed: 21040726]

11. Nunes SS, et al. Biowire: a platform for maturation of human pluripotent stem cell-derived cardiomyocytes. Nature methods. 2013; 10:781-787. DOI: 10.1038/nmeth.2524 [PubMed: 23793239]

12. Chun YW, et al. Combinatorial polymer matrices enhance in vitro maturation of human induced pluripotent stem cell-derived cardiomyocytes. Biomaterials. 2015; 67:52-64. DOI: 10.1016/ j.biomaterials.2015.07.004 [PubMed: 26204225]

13. Ruan JL, et al. Mechanical Stress Promotes Maturation of Human Myocardium From Pluripotent Stem Cell-Derived Progenitors. Stem cells. 2015; 33:2148-2157. DOI: 10.1002/stem.2036 [PubMed: 25865043]

14. Rog-Zielinska EA, et al. Glucocorticoids promote structural and functional maturation of foetal cardiomyocytes: a role for PGC-1alpha. Cell death and differentiation. 2015; 22:1106-1116. DOI: 10.1038/cdd.2014.181 [PubMed: 25361084] 
15. Yang X, et al. Tri-iodo-l-thyronine promotes the maturation of human cardiomyocytes-derived from induced pluripotent stem cells. Journal of molecular and cellular cardiology. 2014; 72:296304. DOI: 10.1016/j.yjmcc.2014.04.005 [PubMed: 24735830]

16. Robertson C, Tran DD, George SC. Concise review: maturation phases of human pluripotent stem cell-derived cardiomyocytes. Stem cells. 2013; 31:829-837. DOI: 10.1002/stem.1331 [PubMed: 23355363]

17. Smolich JJ. Ultrastructural and functional features of the developing mammalian heart: a brief overview. Reproduction, fertility, and development. 1995; 7:451-461.

18. Kane C, Couch L, Terracciano CM. Excitation-contraction coupling of human induced pluripotent stem cell-derived cardiomyocytes. Frontiers in cell and developmental biology. 2015; 3:59. [PubMed: 26484342]

19. Knollmann BC. Induced pluripotent stem cell-derived cardiomyocytes: boutique science or valuable arrhythmia model? Circulation research. 2013; 112:969-976. discussion 976. DOI: 10.1161/CIRCRESAHA.112.300567 [PubMed: 23569106]

20. Lundy SD, Zhu WZ, Regnier M, Laflamme MA. Structural and functional maturation of cardiomyocytes derived from human pluripotent stem cells. Stem Cells Dev. 2013; 22:1991-2002. DOI: 10.1089/scd.2012.0490 [PubMed: 23461462]

21. Mihic A, et al. The effect of cyclic stretch on maturation and 3D tissue formation of human embryonic stem cell-derived cardiomyocytes. Biomaterials. 2014; 35:2798-2808. DOI: 10.1016/ j.biomaterials.2013.12.052 [PubMed: 24424206]

22. Kadota S, Pabon L, Reinecke H, Murry CE. In Vivo Maturation of Human Induced Pluripotent Stem Cell-Derived Cardiomyocytes in Neonatal and Adult Rat Hearts. Stem cell reports. 2017; 8:278-289. DOI: 10.1016/j.stemcr.2016.10.009 [PubMed: 28065644]

23. Laugwitz KL, et al. Postnatal isl1+ cardioblasts enter fully differentiated cardiomyocyte lineages. Nature. 2005; 433:647-653. DOI: 10.1038/nature03215 [PubMed: 15703750]

24. Genead R, et al. Islet-1 cells are cardiac progenitors present during the entire lifespan: from the embryonic stage to adulthood. Stem Cells Dev. 2010; 19:1601-1615. DOI: 10.1089/scd.2009.0483 [PubMed: 20109033]

25. Uosaki H, Taguchi YH. Comparative Gene Expression Analysis of Mouse and Human Cardiac Maturation. Genomics, proteomics \& bioinformatics. 2016; 14:207-215. DOI: 10.1016/j.gpb. 2016.04.004

26. Cho GS, et al. Neonatal Transplantation Confers Maturation of PSC-Derived Cardiomyocytes Conducive to Modeling Cardiomyopathy. Cell reports. 2017; 18:571-582. DOI: 10.1016/j.celrep. 2016.12.040 [PubMed: 28076798]

27. Espuny-Camacho I, et al. Hallmarks of Alzheimer's Disease in Stem-Cell-Derived Human Neurons Transplanted into Mouse Brain. Neuron. 2017; 93:1066-1081 e1068. DOI: 10.1016/ j.neuron.2017.02.001 [PubMed: 28238547]

28. Shenje LT, et al. Precardiac deletion of Numb and Numblike reveals renewal of cardiac progenitors. eLife. 2014; 3:e02164. [PubMed: 24843018]

29. Lee DI, et al. PDE5A suppression of acute beta-adrenergic activation requires modulation of myocyte beta-3 signaling coupled to PKG-mediated troponin I phosphorylation. Basic research in cardiology. 2010; 105:337-347. DOI: 10.1007/s00395-010-0084-5 [PubMed: 20107996]

30. Tandon N, et al. Electrical stimulation systems for cardiac tissue engineering. Nature protocols. 2009; 4:155-173. DOI: 10.1038/nprot.2008.183 [PubMed: 19180087]

31. Shin J, et al. Single-Cell RNA-Seq with Waterfall Reveals Molecular Cascades underlying Adult Neurogenesis. Cell stem cell. 2015; 17:360-372. DOI: 10.1016/j.stem.2015.07.013 [PubMed: 26299571]

32. Laflamme MA, et al. Cardiomyocytes derived from human embryonic stem cells in pro-survival factors enhance function of infarcted rat hearts. Nature biotechnology. 2007; 25:1015-1024. DOI: $10.1038 /$ nbt1327 


\section{Editorial summary}

This protocol describes how to generate mature adult-like cardiomyocytes by culturing mouse or human PSCs in vitro initially and then transferring to neonatal rats for further cell maturation. 


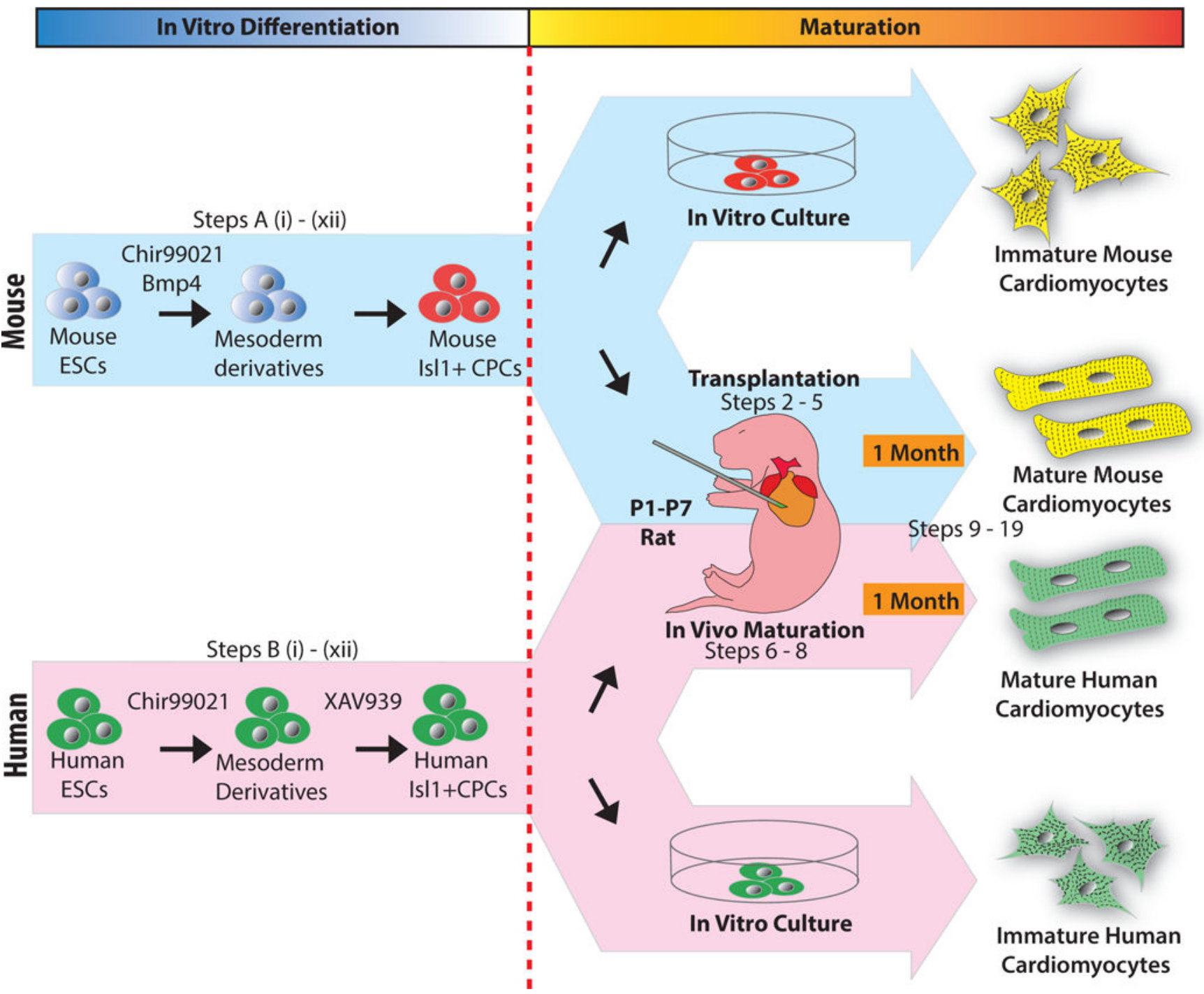

Figure 1.

Experimental protocol for in vivo and in vitro cardiomyocyte maturation. Left: Schematic illustration showing in vitro differentiation of mouse Is11+ CPCs in red and human Isl1+ CPCs in green. Right: in vitro vs. in vivo maturation of cardiomyocytes derived from mouse and human-PSCs. 

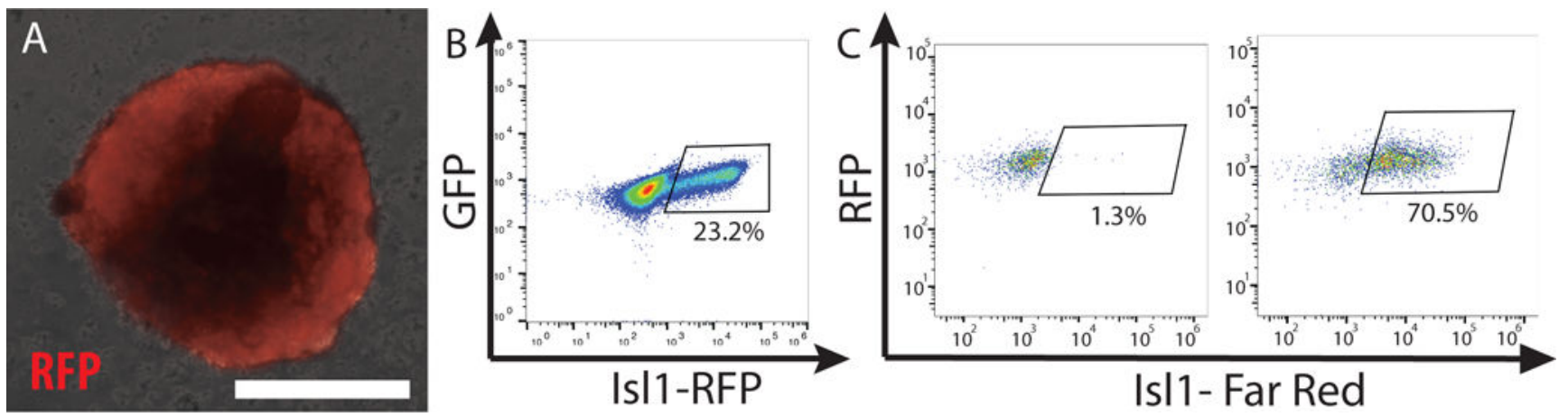

Figure 2.

Is11 positive cardiac progenitor cells. A. Isl1-Cre driven expression of Red Fluorescent Protein (RFP) in a mouse embryoid body. B. RFP+ CPCs are purified by FACS. (62,000 live cells were sorted 14,410 of those were Isl1-positive (23.3\%)). C. Immunostaining for Is11 and flow cytometry analysis of fixed human CPCs. Left plot: negative control with only secondary antibody. (2384 cells were analyzed and of those 31 were only Isl1-positive $(1.3 \%)$ ). Right plot: immunostaining with Isl1 primary antibody. (2750 cells were analyzed and of those 1940 were Isl1-positive (70.3\%)). Scale bar $50 \mu \mathrm{m}$. 
A)
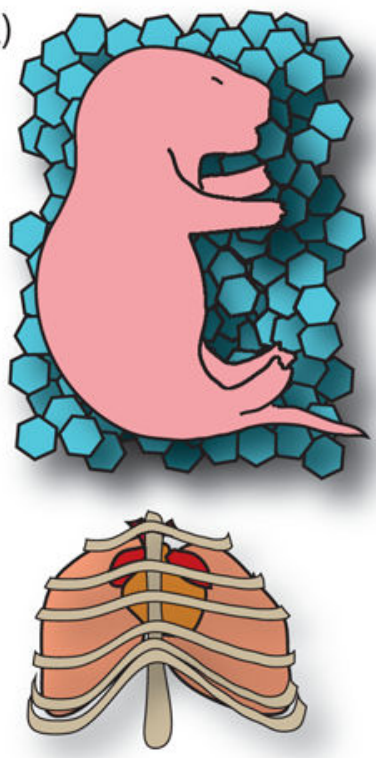

B)

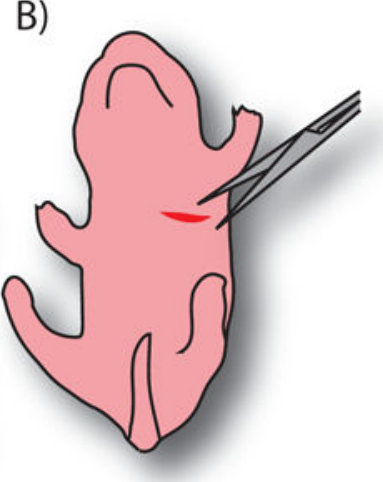

C)
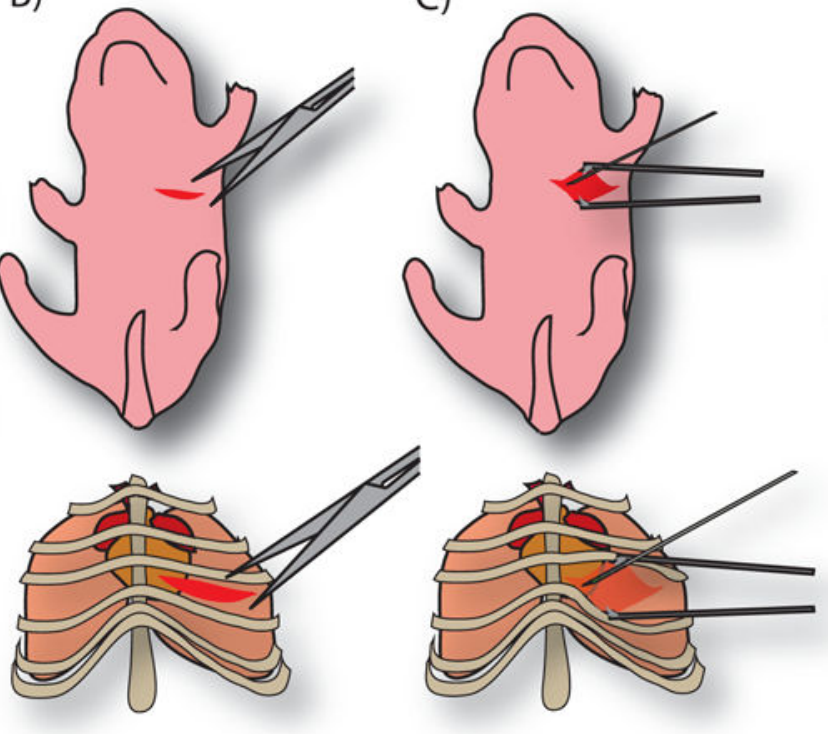

D)
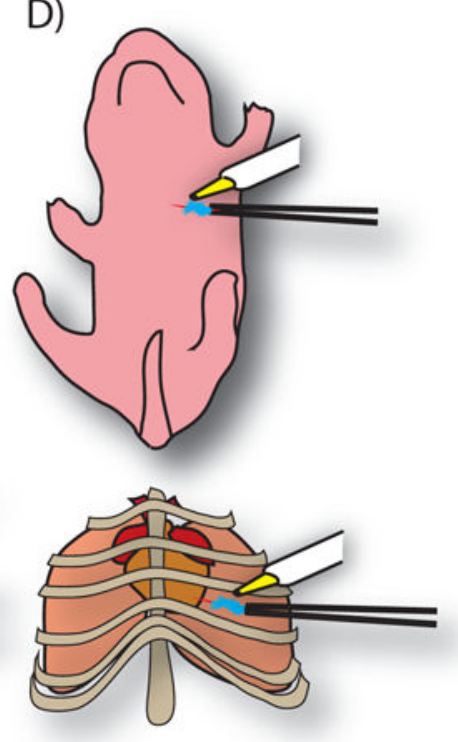

Figure 3.

Surgical transplantation of cardiac progenitor cells for in vivo maturation. A. Neonatal rats 1-7 days old are placed on ice to induce anesthesia. B. Use the fine scissors to make a $\sim 5$ $\mathrm{mm}$ incision in the skin between the third and fourth ribs and gently separate the skin from the underlying muscles using fine forceps. Dissect the muscles of the intercostal space to create an opening of $\sim 4 \mathrm{~mm}$ using the forceps $\mathbf{C}$. Inject CPCs to the left ventricular apex using a microneedle connected to the Eppendorf FemtoJet Microinjector. D. Pinch the edges of the incision with the forceps and no more than $5 \mu \mathrm{L}$ of the tissue adhesive glue to seal it the incision. 

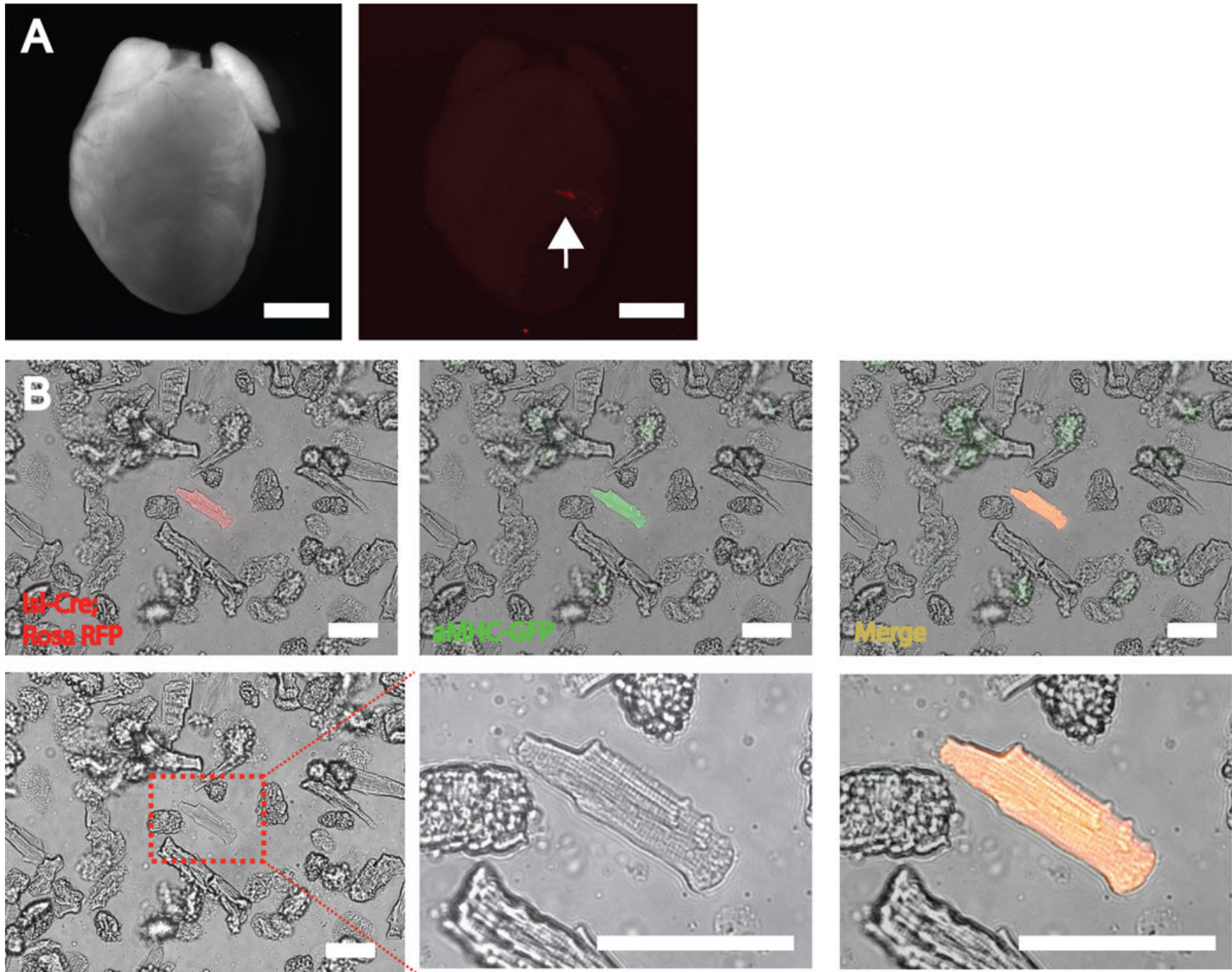

Figure 4.

Isolation of mESC-CMs from injected rat hearts. A. Isolated rat hearts with injected RFP+ mouse CMs (arrow). Scale bars $500 \mathrm{~mm}$. B. Isolated adult-like mESC-CMs after processing of injected rat heart. The injected mESC-CMs are marked with GFP. Scale bars $100 \mu \mathrm{m}$. 

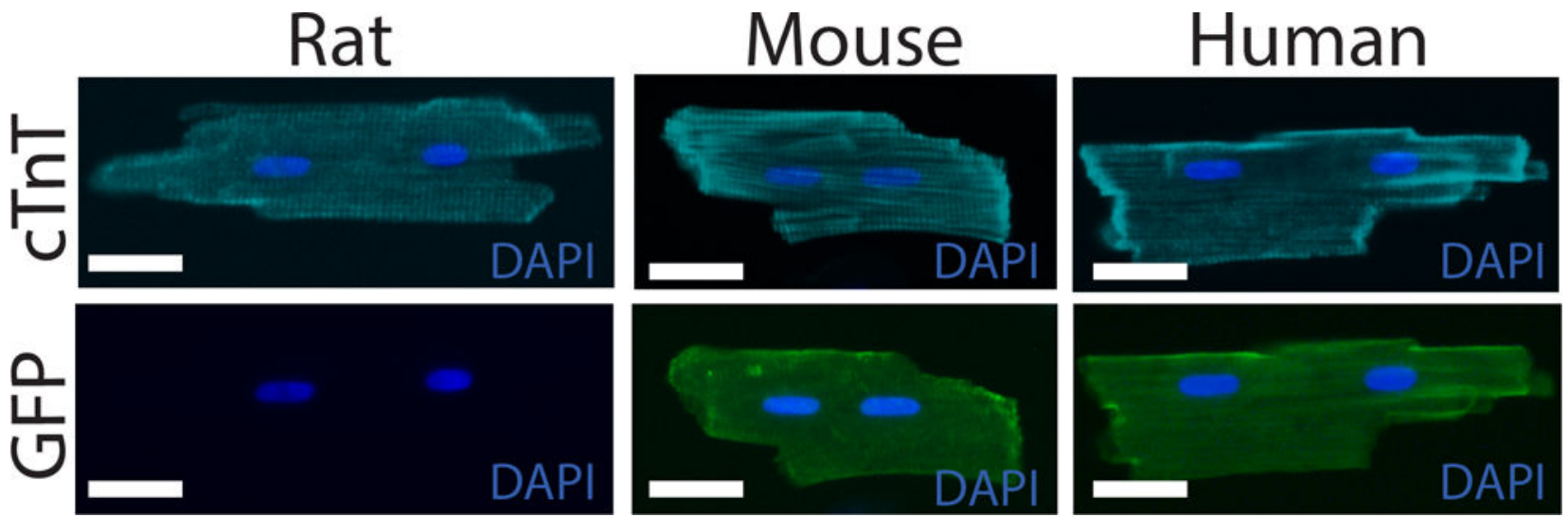

Figure 5.

In vivo matured mouse and human PSC-cardiomyocytes. Injected mouse and human cardiomyocytes were identified by GFP expression. In vivo matured CMs had sarcomere structure, size and binucleation very similar to adult CMs. cTnT: cardiac Troponin T. For all animal experiments appropriate institutional regulatory board permission was obtained. Scale bars $25 \mu \mathrm{m}$. 